Technical

Memorandum

\title{
A CAPACITIVE MANOMETER
}

R. S. Jamies on

\section{LEGAL NOTICE}

This report was prepared as an account of Government sponsored work. Neither the United States, nor the Commission, nor any person acting on behalf of the Commission:

A. Makes any warranty or representation, express or implied, with respect to the accuracy, completeness, or usefulness of the information contained in this report, or that the use of any information, apparatus, method, or process disclosed in this report may not infringe privately owned rights; or

B. Assumes any liabilities with respect to the use of, or for damages resulting from the use of any information, apparatus, method, or process disclosed in this report.

As used in the above, "person acting on behalf of the Commission" includes any employee or contractor of the Commission to the extent that such employee or contractor prepares, handles or distributes, or provides access to, any information pursuant to his employment or contract with the Commission.

\section{ABSTRACT}

A discussion is presented of the advantages of reading a mercury column manometer by means of the variable capacitance existing between the mercury column and a metallic coating plated on the outside of the barometric column. Also, a method is presented for converting the capacitance to a digital reading of pressure.

Case No. 435.01

\begin{tabular}{l} 
Photostat Price \$ $\$ 100$ \\
Microfilm Price $\$ 180$ \\
Available from the \\
Office of Technical Services \\
Department of Commerce \\
Washington 25, D. C. \\
\hline
\end{tabular}




\section{DISCLAIMER}

This report was prepared as an account of work sponsored by an agency of the United States Government. Neither the United States Government nor any agency Thereof, nor any of their employees, makes any warranty, express or implied, or assumes any legal liability or responsibility for the accuracy, completeness, or usefulness of any information, apparatus, product, or process disclosed, or represents that its use would not infringe privately owned rights. Reference herein to any specific commercial product, process, or service by trade name, trademark, manufacturer, or otherwise does not necessarily constitute or imply its endorsement, recommendation, or favoring by the United States Government or any agency thereof. The views and opinions of authors expressed herein do not necessarily state or reflect those of the United States Government or any agency thereof. 


\section{DISCLAIMER}

Portions of this document may be illegible in electronic image products. Images are produced from the best available original document. 


\section{A CAPACITIVE MANOMETER}

\section{INTRODUCTION}

Division 5351 has investigated the possibility of reading pressure-altitudes without the use of moving parts or pressure capsules. In this study, a means of more accurate pressure measurement was sought, as was a means of making such readings as automatic as possible. This was done with a view towards the improvement of baroswitch testing; however, the results of the study are capable of such wide application that they are presented herein for distribution.

The mercury column barometer is the universal pressure standard in use in pressure altitude measurements. The National standard as well as the Corporation standards are of this type. The accuracy of a mercury manometer is higher than that of gauge-type instruments; thus, in any measurement not requiring portable instruments the mercury manometer is preferred. The greatest difficulty in obtaining accurate readings on a mercury barometer has been in reading the meniscus. In the usual method, a hairline (or the edge of an opaque solid) is aligned by eye tangentially to the meniscus, and the position of the hairline read on a linear scale. The hairline often obscures enough of the meniscus to cast doubt on the location of the tangent; parrallax often causes errors in the reading of the scale. It is often difficult to read the scale or see the meniscus when the manometer is enclosed in a temperature controlled cabinet. When many measurements are being taken, operator fatigue becomes another source of error.

Many ways of eliminating the visual meniscus reading have been tried; among which are photocell and servo-mechanism methods. In the former system, photocells are placed at fixed points on the mercury column; when the mercury.. column interrupts a light beam directed at the photocell a change in output is registered. This system lacks flexibility in that only fixed points may be read. In addition, errors are caused by diffraction of the light beam, and aging of the photocell. In the servo system, a light beam and two photocells are kept aligned with the top of the mercury column by a servomechanism. One photocell must be shadowed by the column while the other is not, before the driving mechanism will come to rest. The gear train that moves the photocells also turns a counter or indicator which shows the light cell position in pressure units. Errors in this system are caused by backlash, friction, photocell errors and the distance between the photocells. The system also has a dynamic lag when the moving mercury column leaves the mechanism behind. 


\section{HISTORY OF DEVELOPMENT}

Division 5351 investigated the possibilities of measuring mercury-column heights without using physical moving parts. Some of the methods consiciered were:

1. Using the mercury column to short out a resistor.

2. Measuring the inductance of the column.

3. Measuring the capacitance between the column and a conductive coating outside the glass tube.

It was felt that the first method would introduce contamination in the column, so it was discarded. The second method required a contact that would float on the top of the column, and a contact in the mercury pool. The electrical lead from the floating contact would have to be brought out through the vacuum seal in the top of the glass tube, which would present difficulties in maintaining the seal. This lead would also have to bend and coil as the floating contact approached the top of the column, which would put a varying force on the floating contact, introducing errors. It was felt that these physical difficulties were too great; a model was not built. The third method, using capacitance, seemed the most promising. In this method, a contact would be inserted in the mercury pool; the outside of the glass tube would be coated with silver over the area that normally would be read visually. A contact would be put on this silver sheath. (Please see Figure 1.) As the the pressure increases in the manometer the mercury would rise, placing a greater surface of mercury inside the coated portion of the tube. This increases the capacitance between the mercury and the silver sheath. The capacitance between two plates is a function of the area $A$, common to the plates, distance, $d$, between the plates, and the dielectric constant, $K$, of the insulator between the plates in the following manner:

$$
\mathrm{C}=0.2244 \frac{\mathrm{KA}}{\mathrm{d}} \text { (in English units) }
$$

where $0: 2244$ is a constant of proportionality. Thus, it was expected that the capacitance would vary linearly with the mercury column height, assuming that the tube was of uniform thickness and diameter.

An experimental model was built and tested. The manometer used was a Wallace and Tiernan model FA-135 pool-type manometer. The glass tube was not ground; common barometer mercury was in the pool. The tube was coated with a solid silver coating by, first, a hot flash of silver, and second, an electrolytic plating. A wire wrapped around the tube before plating acted as a terminal. After reassembly, a stainless steel machine screw was inserted in the mercury pool for the other terminal. The entire assembly was shielded by screening. A shielded, 
two conductor cable was attached to the terminals and connected to a capacitance bridge. The pressures were monitored by the Department 5350 Hass Manometer, which is a calibrated tertiary standard. At a sea level standard pressure, the capacitance bridge was balanced with a standard variable capacitor placed in parallel with the manometer capasitor terninals. As pressure decreased, the capacitance decreased, and the variable standard capacitor was adjusted to bring the bridge back into balance, and changes in capacitance for changes in pressure were recorded. When the data was plotted, the characteristic was found to be linear, within the accuracy of the test equipment. (see Figure II.)

The capacitance between a mercury columr and a concucting coating on the outside of the manometer tube can be used to indicate the pressure differential in the manometer. The variation of capacitance with pressure is linear, thus a manometer with this system can be calibrated in capacitance as a direct function of frequency.

\section{A METHOD FOR DETECTING MANOMETER CAPACITANCE}

The complete manometer would consist of two paris:

1. The transducer.

2. The detector.

The transducer would consist of the capacitive manometer in its housing. The detector would have several components:

1. An oscillator.

2. A power supply.

3. A trequency meter。

4. A recorder (optional).

The oscillator should operate at a radio frequency, about 10 megacycles. This would take full advantage of the frequency meter's capabilities.

The capacitance of the mancmeter could be fed to a radio-frequency oscillator along short, fixed leads. The oscillator frequency would then be a nonlinear function of capacitance (and pressure). A digital frequency meter, such as the Berkeley 0-42 megacycle frequency meter, could be used to monitor the frequency. A digital printer could be used to register the frequency at any desired point; such as the closure point of a baroswitch. The printer would read the output of the frequency meter, and would print either manualiy or from trigger signals. Please see Figure III.

The temperature variations at ambient will have an effect on the manometer and oscillator, hence they must be enclosed in a constant temperature cabinet. If 
the temperature cabinet is shielded, the capacitor and oscillat or will be protected against stray pick-up. The output of the oscillator can be fed to the Berkeley Counter through shielded leads; the counter need not be in the temperature cabinet.

One major problem. likely to be encountered in developrnent of the capacitor manometer is the oscillator stability. The oscillator should have a high degree of accuracy, to best exploit the accuracy of the Berkeley Counter. If the oscillator. temperature is controlled closely, and cabinet is well shielded, the greatest portion of drift should come from the power supply. There are power supplies which are held to a voltage change of .01 per cent; use of one of these should minimize drift. The use of a buffer amplifier between the oscillator and counter should also help to minimize drirtt.

Another problem common to all mercury manometers is that of dirt and contamination in the mercury with repeated readings. The presence of dirt will cause a considerable amount of mercury to stick to the tube walls, this would also cause errors in the capacitance. The only cure for this condition is regularly scheduled cleanings of the tube and the mercury.

If the oscillator can be built to hold a frequency within one part in a million for a certain capacitance value, its accuracy will be commensurate with that of the frequency meter. Oscillators of such high accuracy are commonly used in frequency-modulation broadcasting, and should be feasible in this application. The accuracy of the Berkeley Frequency Meter is one part in ten million \pm 1 cycle per second when calibrated to the Bureau of Standards signal broadcast by station WWV. This calibration could be performed daily, and is accomplished by simply turning a knob. The greatest error source in the system would then be in non-uniformities in the tube thickness and diameter, and the accuracy of calibration. It is probable that these errors will be much greater than the detector errors. At the calibration points, the accuracy will depend almost exclusively on the calibration. In between calibration points, irregularities in the tube will add to the calibration errors. A precision ground tube will minimize these errors, by making the capacitance more linear between calibrated points. The overall accuracy of the system should easily exceed $0.1 \mathrm{~mm}$ of $\mathrm{Hg}$, or 1 part in 8000. This figure is a minimum accuracy necessary for baroswitch work in the foreseeable future. With reas onable care, it is expected that a manometer of this type could be constructed with accuracies exceeding those of the Corporation and National standards.

Since the relation of oscillator frequency to pressure is not linear, one end of the scale will have a much greater sensitivity than the other. If this is appreciable, it may be overcome by dividing the pressure range of 0 to $760 \mathrm{~mm}$ of $\mathrm{Hg}$ into several ranges. At each range boundary, a fixed capacitor may be switched in 
parallel with the manometer capacitor, thus operating over one portion of the frequency-pressure curve several times.

In a baroswitch tester application, the digital printer should be used. Closure of a contact would cause the printer to register the closure frequency on paper. Calibration tables would be used to convert this frequency to a pressure or aititude. The present baroswitch testing method uses an operator watching 4 neon bulbs. On closure, a neon bulb lights up and the operator looks at an altimeter and records the reading. Fatigue error is high in this system when many measurements are made.

There are other, less expensive, methods for reading the capacitor output. However, the accuracies of these methods are low, in proportion to their cost. One such method is to replace the Berkeley Frequency Meter with a non-digital type. However, this type of meter cannot be read to one cycle in ten million, the best accuracy of the system would be about one part in two hundred, which is not as good as that of the glass tube. Another methoo would use a capacitance bridge. The accuracy of this method would not be much better than one part in two hundred. These figures compare unfavorably with the accuracy of the Has s Mercury column visual manometer used in Department 5350 which is accurate to $0.1 \mathrm{~mm}$ of $\mathrm{Hg}$.

Although not suitable for field use, with the possible exception of a field standard, the capacitor manometer should have many useful applications at Sandia Corporation. For example, the capacitor manometer would provide a means of accurate and rapid testing and adjustment of baroswitches, giving a method free from operator fatigue errors. Also, many standards in the corporation could be made of this type, making calibration of associated equipment faster and more accurate.

The preliminary investigation of the capacitor manometer principle was done by Department 5350. However, since the development of this device is outside the proper dominion of this organization, this information is being distributed for the use of those more directly associated with the development pressure testing devices in the expectation that they may find it of use.

DISTRIBUTION:

F. J. Given, 5300

A. F. Cone, 1510

G. H. Roth, 1520

T. B. Morse, 1610

H. C. Biggs, 1650

R. J. Bradfora, 2540

P. G. Fredrickson, 2550
$+19154$

R. J. Dill, 2560

D. B. Shuster, 5220

J. I. Hegge, 5350

E. L. Deeter, 5430

M. L. Craig, 5351 (3)

File, 5352

G. Byrne, 1922-2

Case No. 435.01

$\mathrm{March} 23,1954$ 


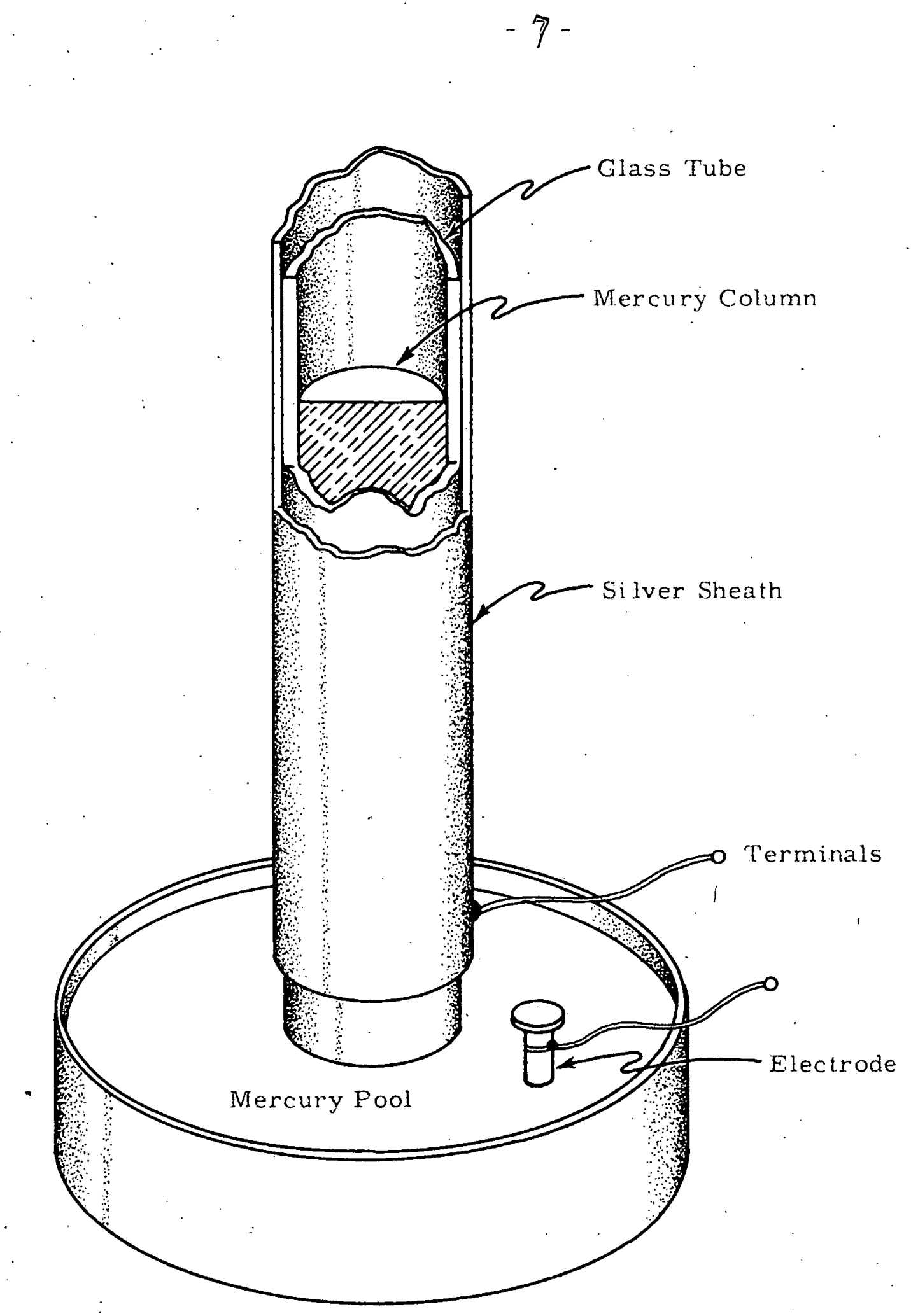

Figure I 


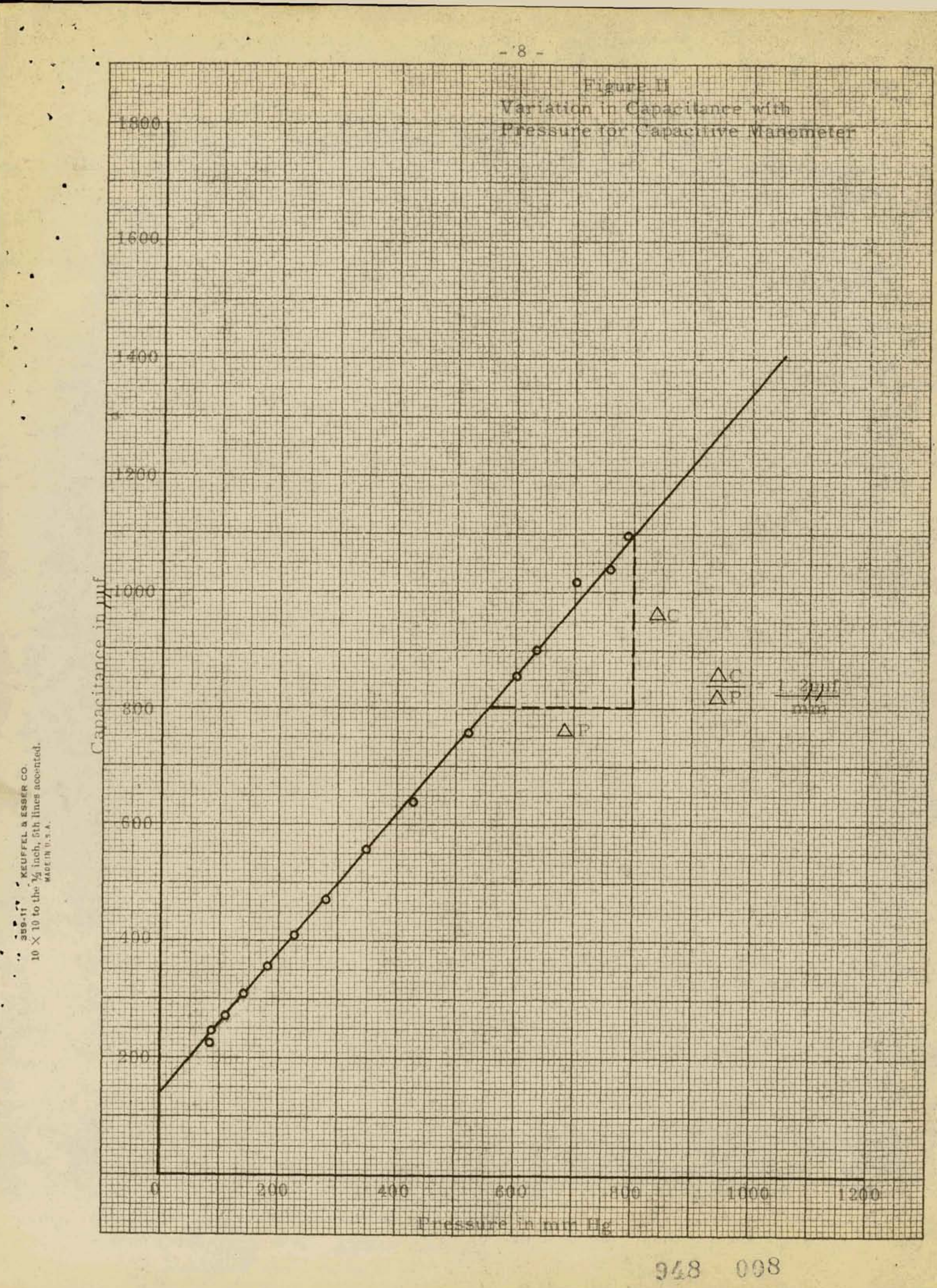





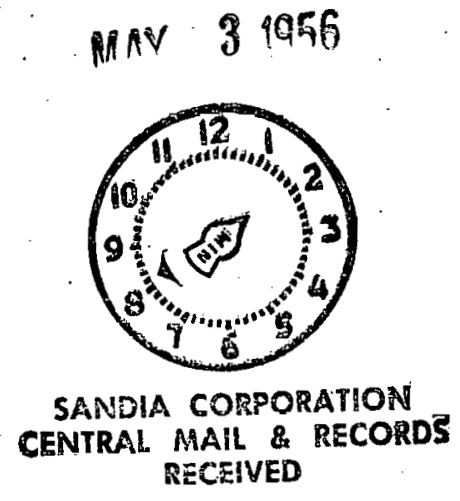

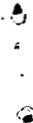

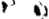

4

a
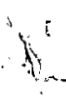

SANDIA CORPORATION
CENTRAL MAIL \& RECORDS RECEIVED

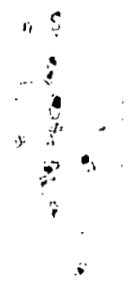


